\title{
Capsaicin and Piperine as Functional Excipients for Improved Drug Delivery across Nasal Epithelial Models
}

Authors

Werner Gerber $^{1}$, Dewald Steyn ${ }^{1}$, Awie Kotzé ${ }^{1}$, Hanna Svitina ${ }^{1}$, Ché Weldon ${ }^{2}$, Josias Hamman ${ }^{1}$

Affiliations

1 Centre of Excellence for Pharmaceutical Sciences, NorthWest University, Potchefstroom, South Africa

2 Unit for Environmental Sciences and Management, NorthWest University, Potchefstroom, South Africa

\section{Key words}

Bioenhancer, capsaicin, piperine, FITC-dextran 4400, rhodamine 123, RPMI 2650, nasal delivery

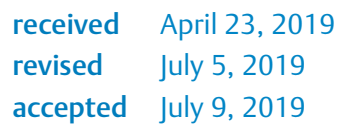

\section{Bibliography}

DOI https://doi.org/10.1055/a-0978-5172

Published online July 24, 2019 | Planta Med 2019; 85: 11141123 @ Georg Thieme Verlag KG Stuttgart · New York | ISSN 0032-0943

\section{Correspondence}

Prof. Josias Hamman, PhD

Centre of Excellence for Pharmaceutical Sciences, North-West University

Private Bag X6001, 2520 Potchefstroom, South Africa

Phone: + 27182994035 , Fax: + 27182992248

sias.hamman@nwu.ac.za

\section{ABSTRACT}

The fruit from various pepper plants has been employed for the seasoning of food, as perfuming agents, and also as traditional medicines. Phytochemicals isolated from different pepper species have been found to modulate the pharmacokinetics of orally administered drugs. This study investigated the possibility to apply capsaicin and piperine (extracted alkaloids) as modulators for drug delivery across the nasal epithelium. Both a nasal epithelial cell line (RPMI 2650) and excised sheep nasal tissue were used as models to investigate the effects of the selected pepper compounds on drug permeation. FITC-dextran 4400 (MW $4400 \mathrm{Da}$ ) was used as a large molecular weight marker compound for paracellular transport, while rhodamine 123 was used as a marker compound that is a substrate for P-glycoprotein-mediated efflux. From the permeation results, it was clear that capsaicin inhibited P-glycoprotein efflux to a larger extent, while piperine showed drug permeation enhancement via other mechanisms. The cell cytotoxicity studies indicated that capsaicin was noncytotoxic up to a concentration of $200 \mu \mathrm{M}$ and piperine up to a concentration of $500 \mu \mathrm{M}$ as indicated by cell viability above $80 \%$. The histological analysis of the excised nasal tissue and cultured RPMI 2650 cell layers indicated that some damage occurred after treatment with $200 \mu \mathrm{M}$ capsaicin, but no changes were observed for piperine up to a concentration of $50 \mu \mathrm{M}$.

$\begin{array}{ll}\text { ABBREVIATIONS } \\ \text { ALI } & \text { air-liquid interface } \\ \text { FD4 } & \text { FITC-dextran } 4400 \\ \text { KRB } & \text { Krebs-Ringer bicarbonate buffer } \\ \text { LCC } & \text { liquid-covered culture } \\ \text { MEM } & \text { modified Eagle's medium } \\ \text { Papp } & \text { apparent permeability coefficient } \\ \text { P-gP } & \text { P-glycoprotein } \\ \text { PTP } & \text { polyethylene terepthalate } \\ \text { R123 } & \text { rhodamine 123 } \\ \text { TEER } & \text { transepithelial electrical resistance } \\ \text { TRPV1 } & \text { transient receptor potential vanilloid 1 }\end{array}$

\section{Introduction}

Chili pepper (family Solanaceae) and black pepper (family Piperaceae) are annual herbs grown in warm climates. The production thereof is globally regarded as one of the most important economical and agricultural activities in developed and developing countries. The fruits of these plants are widely used in the flavoring of cuisine, especially in Asia and South America, and have also found applications in the cosmetic industry and for medicinal uses [1,2].

Capsaicin ( $\vee$ Fig. $1 \mathrm{~A}$ ) is one of the main capsaicinoids uniquely present in the fruit of plants from the genus Capsicum. These plants have been known for their medicinal value, with Mayan pharmacopoeia reporting the application of chili peppers in respiratory and bowel ailments, relief of earaches, and in the treatment of wounds [3]. It is now also known that capsaicin is able to inhibit melanoma proliferation, induce apoptosis in human mammary glands, and is capable of inhibiting P-gp efflux transporters in the 


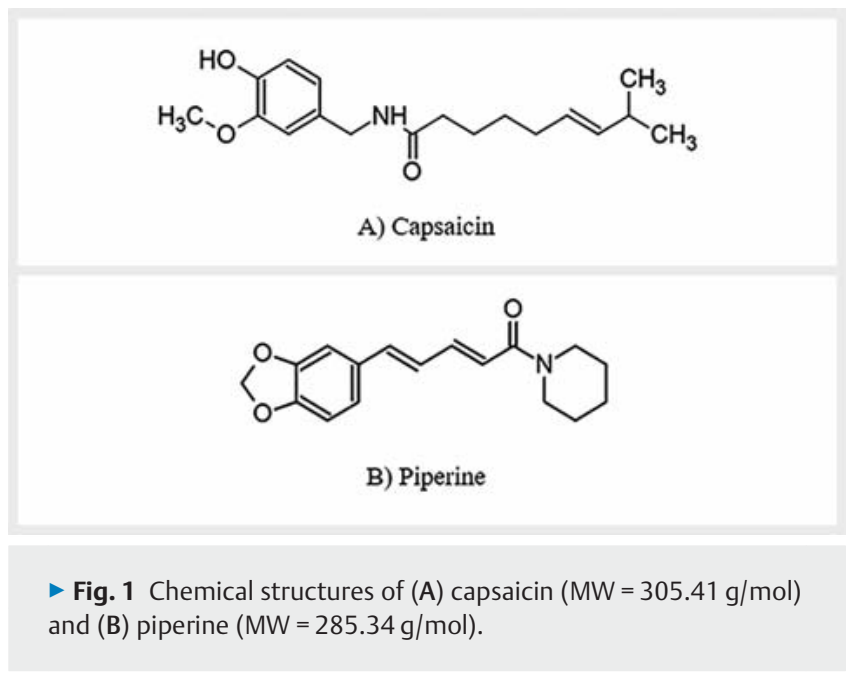

Caco-2 (human colon adenocarcinoma) and KB-C2 (human papillomavirus-related endocervical adenocarcinoma) cell lines [4]. In addition, it was proven that capsaicin presents with analgesic, antimicrobial, and antioxidant effects [1,3].

Black pepper (Piper nigrum L.) and long pepper (Piper longum L.) belong to the genus Piper for which piperine ( $\bullet$ Fig. 1 B) is the major alkaloid and is responsible for the pungent taste of the fruits of both. Piperine has long been used as a traditional medicine, preservative, and insecticide in addition to the more commonly known seasoning and perfuming applications. Piperine has also been proven to be effective in improving the pharmacokinetics of poorly bioavailable drugs and other medicinal herbs through inhibiting P-gp and CYP450 metabolism in intestinal epithelial cells [2, 5-7].

The effects of capsaicin and piperine on the permeation of compounds have been tested in different cell models (i.e., Caco2 and MDCK II cells) for potentially improved delivery of drug compounds, but they have not yet been explored for improved nasal delivery of drug compounds. Nasal delivery of drugs holds certain benefits for the systemic delivery of drugs, including a rich blood supply and an epithelium that is relatively more permeable in comparison with other areas in the body, and it circumvents first-pass metabolism. Furthermore, with a relatively large surface area $\left(150 \mathrm{~cm}^{2}\right)$ and volume $(15-20 \mathrm{~mL})$, the nasal cavity provides an alternative route for self-administration of poor orally bioavailable drug products that would have otherwise been administered via the parenteral route [8-10].

In the current study, the effects of capsaicin and piperine were investigated on the permeation of two model compounds in two nasal epithelial models. The RPMI 2650 cell line is currently the only commercially available human nasal epithelial cell line. When grown under the correct ALI conditions, RPMI 2650 cells have been found to express P-gp, multidrug resistance proteins, and tight junctions. Furthermore, even though the model presents with multilayered cells, the TEER and permeability properties are comparable to that of the human nasal mucosa $[8,11,12]$. The excised sheep nasal mucosa model has been proven to be well suited for permeation and metabolism studies related to the nasal delivery of compounds. This model is more cost-effective than comparable in vitro and in vivo models, and sheep nasal tissue is easily accessible from abattoirs. The sheep nasal model has been found to closely resemble nasal absorption in humans [13]. In addition, comparable TEER values have been reported between sheep and human nasal epithelium, and the sheep nasal tissue also expresses P-gp efflux transporters [14, 15].

\section{Results and Discussion}

Validation results of the analysis by fluorescent spectroscopy of marker compounds used in the permeability studies are shown in - Table 1. R123 was used as a marker for efflux-mediated transport, while FD4 was used as a macromolecular marker for paracellular transport.

Linearity and purity of the two pepper extracts, capsaicin and piperine, that were evaluated/screened for possible pharmacokinetic interactions were determined using HPLC analysis ( $\bullet$ Table 2). Linearity was determined using reference standards of each compound, whereas purity is expressed as a percentage of raw material in relation to the reference standards. The concentrations of the reference standard were $250 \mu \mathrm{g} / \mathrm{mL}$ for capsaicin and $150 \mu \mathrm{g} / \mathrm{mL}$ for piperine.

The $\mathrm{P}_{\text {app }}$ values of FD4 across RPMI 2650 epithelial cell layers in the apical-to-basolateral direction are shown in $\mathbf{F i g} \mathbf{2}$ in the absence (FD4 alone, control group) and presence of different concentrations of capsaicin $(50,100$, and $200 \mu \mathrm{M})$ and piperine $(10$, 25 , and $50 \mu \mathrm{M})$.

From - Fig. 2, it is clear that capsaicin increased the FD4 permeation ( $\mathrm{P}_{\mathrm{app}}$ ) across RPMI 2650 nasal epithelial cell layers at all the concentrations applied, which was to some extent inversely proportional to the capsaicin concentration. However, the permeation of FD4 was statistically significantly higher than the control (FD4 alone) only at the lowest concentration of capsaicin ( $50 \mu \mathrm{M})$ applied. In general, these findings in the nasal epithelial cell line are in coherence with previous findings obtained for capsaicin across different epithelial models such as the Caco- 2 cell model $[16,17]$ and the MDCK II model $[18,19]$. In both these previous sets of studies, it was found that capsaicin reduced TEER and increased paracellular permeation of different compounds by means of tight junction modulation. It was suggested that capsaicin can open tight junctions via a unique and reversible dual-action mechanism. Firstly, capsaicin caused an influx of $\mathrm{Ca}^{2+}$ into the cells, which led to cofilin dephosphorylation that directly induced depolymerization of F-actin leading to the opening of tight junctions $[1,16]$. Secondly, the total concentration of occludin expression was reduced, while a redistribution of actin at the bicellular tight junctions was seen $[17,19]$. These two mechanisms seemed to occur independently from one another, but both contributed to the increased permeability through the paracellular transport pathway.

In this study, capsaicin had a negligible effect on the TEER (data not shown) of the RPMI 2650 nasal epithelial cell layers. This phenomenon may be explained by the fact that RPMI 2650 cells grow in multilayers (please refer to histology below) and not in monolayers like other epithelial cell models (e.g., Caco-2 and MDCK II cells). The study by Shiobara et al. [19] concluded that capsaicin acted differently on actin at bicellular tight junctions than at tri- 
- Table 1 Fluorescent spectroscopy validation parameters of marker compounds used for permeation studies.

\begin{tabular}{|c|c|c|c|c|c|c|}
\hline & \multicolumn{3}{|l|}{ R123 } & \multicolumn{3}{|l|}{ FD4 } \\
\hline Linearity & \multicolumn{3}{|c|}{$r^{2}=0.999$} & \multicolumn{3}{|l|}{$r^{2}=0.999$} \\
\hline Limit of detection & \multicolumn{3}{|c|}{$0.002 \mu \mathrm{M}$} & \multicolumn{3}{|c|}{$0.005 \mu \mathrm{g} / \mathrm{mL}$} \\
\hline \multirow[t]{2}{*}{ Limit of quantification } & \multicolumn{3}{|c|}{$0.005 \mu \mathrm{M}$} & \multicolumn{3}{|c|}{$0.016 \mu \mathrm{g} / \mathrm{mL}$} \\
\hline & $5 \mu \mathrm{M}$ & $2.5 \mu \mathrm{M}$ & $0.125 \mu \mathrm{M}$ & $125 \mu \mathrm{g} / \mathrm{mL}$ & $62.5 \mu \mathrm{g} / \mathrm{mL}$ & $12.5 \mu \mathrm{g} / \mathrm{mL}$ \\
\hline Accuracy & $98.21 \%$ & $98.14 \%$ & $116.64 \%$ & $95.77 \%$ & $98.27 \%$ & $104.67 \%$ \\
\hline Intraday precision (\%RSD) & $4.97 \%$ & $2.37 \%$ & $6.45 \%$ & $2.77 \%$ & $3.69 \%$ & $2.63 \%$ \\
\hline Inter-day precision (\%RSD) & $4.52 \%$ & $2.16 \%$ & $7.22 \%$ & $2.89 \%$ & $3.52 \%$ & $2.63 \%$ \\
\hline
\end{tabular}

- Table 2 Linearity and purity results of the selected pepper extracts (i.e., capsaicin and piperine) as determined by HPLC.

\begin{tabular}{|l|l|l|}
\hline & Capsaicin & Piperine \\
\hline Linearity & $r^{2}=0.999$ & $r^{2}=0.999$ \\
\hline Purity & $91.82 \%$ & $97.62 \%$ \\
\hline
\end{tabular}

cellular tight junctions. In a multilayer model, such as the RPMI 2650 cells grown on insert membranes, there will be a larger amount of tricellular tight junctions than bicellular tight junctions as compared to that found in monolayer cell models. A probable explanation for the inverse proportion in FD4 permeation as a function of capsaicin concentration across the multilayered RPMI 2650 cells could be attributed to an overall increase in tricellular tight junctions found in the model. Due to this, a saturation of the interactions between the capsaicin and bicellular tight junctions may have already been reached at the lowest concentration $(50 \mu \mathrm{M})$ applied and higher concentrations therefore did not cause any higher permeation enhancement effect.

$\checkmark$ Fig. 2 indicates that piperine increased FD4 permeation pronouncedly across the RPMI cell layers, albeit not statistically significantly $(p>0.05)$. The effect by piperine on FD4 permeation across the RPMI 2650 cell layers did not increase with an increase in piperine concentration over the concentration range investigated $(10-50 \mu \mathrm{M})$. It was previously proposed that piperine led to polarized paracellular opening of the blood-brain barrier [20] and increased drug absorption by fluidizing the brush border membrane while increasing microvilli length [21]. Furthermore, TEER measurements during the current permeation studies indicated a $8.99,8.57$, and $18.69 \%$ decrease in the presence of 10 , 25 , and $50 \mu \mathrm{M}$ piperine, respectively. Since piperine only had a slight decreasing effect on TEER of the RPMI nasal epithelial cell layers, it may therefore have increased FD4 permeation across the RPMI 2650 nasal epithelial cell layers, most probably by a combination of the mechanisms previously proposed. Similar to that observed with capsaicin, piperine also exhibited the maximum effect at the lowest concentration applied and this effect did not increase further with an increase in concentration. Once again, this may be explained by a saturation of the interaction between piperine and the tight junctions at the lowest concentration applied.
The $P_{\text {app }}$ values of the efflux substrate, R123, across RPMI 2650 nasal epithelial cell layers in the apical-to-basolateral (absorptive) and basolateral-to-apical (secretory) directions are shown in - Fig. 3. The $P_{\text {app }}$ values for R123 are shown in the absence (R123 alone, control group) and presence of different concentrations of capsaicin $(50,100$, and $200 \mu \mathrm{M})$ as well as piperine $(10$, 25, and $50 \mu \mathrm{M})$.

Capsaicin increased the permeation of R123 across nasal epithelial RPMI 2650 cell layers in the absorptive direction compared to the control in a concentration-dependent manner, which was statistically significant $(p \leq 0.05)$ at the highest concentration $(200 \mu \mathrm{M})$ applied ( $\bullet$ Fig. 3$)$. Although the secretory permeation was slightly higher than that of the control group, it decreased with an increase in capsaicin concentration and the effect is clearly visible in the efflux ratio values ( $\triangleright$ Table 3 ). The slightly higher permeation in the secretory direction may be explained by other mechanisms, but this was overshadowed by efflux inhibition at higher concentrations of capsaicin. From the permeation results obtained for both FD4 and R123 in the presence of capsaicin, it seems that capsaicin exhibited a larger effect on efflux-related permeation than paracellular permeation. This efflux inhibition effect of capsaicin on nasal epithelial cells correlates well with the efflux inhibition exhibited by capsaicin in other in vitro epithelial cell models such as Caco-2 cells [3] and KB-C2 cells [22]. Additionally, it has also been proven with in vivo models [23].

In the presence of piperine, both absorptive and secretory permeation of R123 increased in a concentration-dependent manner together with a decrease in the efflux ratio value at the highest concentration applied ( $\bullet$ Table 3 ). It was previously shown in the intestinal epithelium that piperine caused efflux inhibition when applied together with a P-gp transporter substrate [6, 24, 25]. However, the results of this study indicated that piperine had a larger modulatory effect on paracellular permeation than on efflux inhibition across the nasal epithelial cells (although efflux inhibition was not explicitly ruled out as seen by the reduced efflux ratio value at the highest concentration). Since R123 is also able to diffuse paracellularly [26], the potential opening of tight junctions by the coapplied piperine correlated well with the increase in $\mathrm{P}_{\text {app }}$ values of R123.

The effect of capsaicin and piperine on the permeation of model compounds was also evaluated across excised sheep nasal tissues. The $\mathrm{P}_{\text {app }}$ values of FD4 across excised sheep nasal epithelial tissues in the apical-to-basolateral direction are shown in $\mathbf{F i g . 4}$ in the absence (FD4 alone, control group) and presence of differ- 
RPMI 2650 cell line
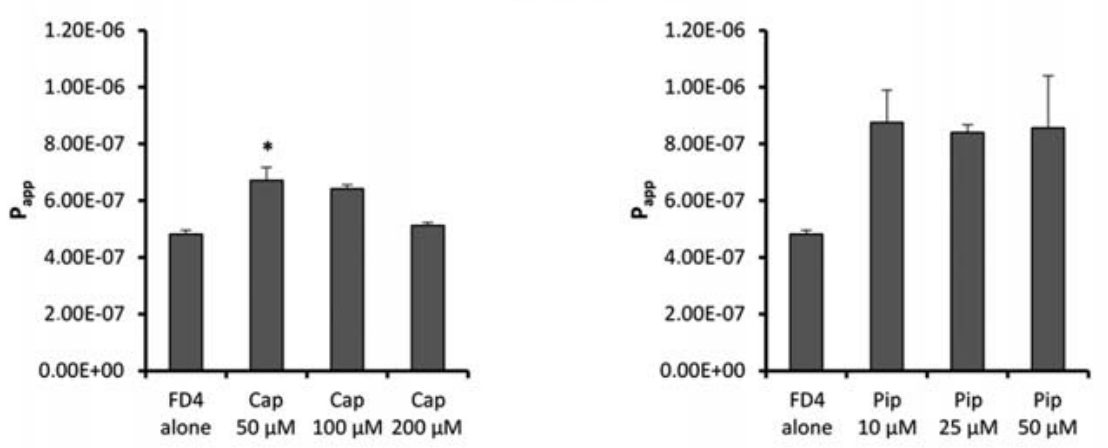

- Fig. $2 P_{\text {app }}$ values of FD4 in the absence (control) and presence of different concentrations of capsaicin (Cap) and piperine (Pip) across RPMI 2650 nasal epithelial cell layers in the absorptive direction $\left({ }^{*} p \leq 0.05\right.$, Kruskal-Wallis test followed by Dunn's post hoc test).

\section{RPMI 2650 cell line}
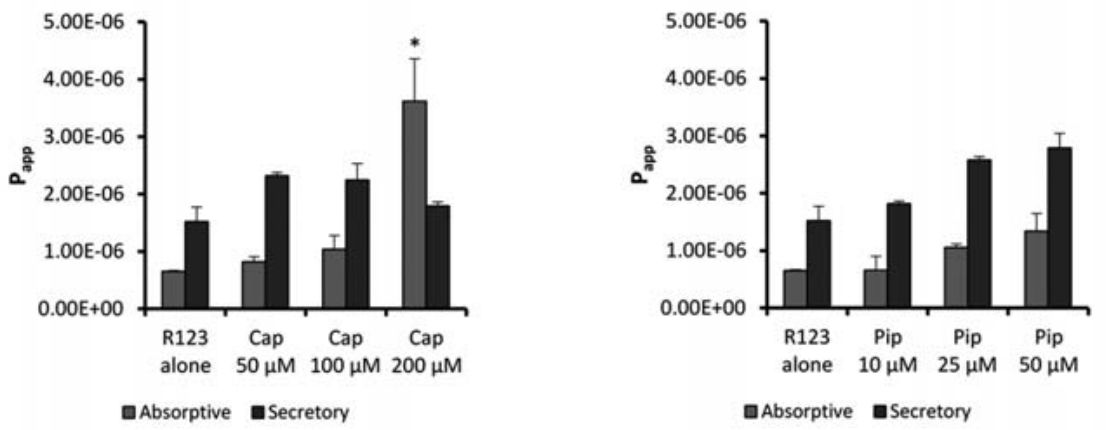

- Fig. $3 \mathrm{P}_{\text {app }}$ values of R123 in the absence (control) and presence of different concentrations of capsaicin (Cap) and piperine (Pip) across RPMI 2650 nasal epithelial cell layers in the absorptive and secretory directions ( ${ }^{*} \mathrm{p} \leq 0.05$, Kruskal-Wallis test followed by Dunn's post hoc test).

- Table 3 Efflux ratio values of R123 in the absence (R123 alone, control) and presence of different concentrations of capsaicin and piperine across RPMI 2650 nasal epithelial cell layers.

\begin{tabular}{|l|l|l|l|l|l|l|l|}
\hline & R123 alone & Capsaicin & \multicolumn{3}{|c|}{ Piperine } \\
\hline & & $\mathbf{5 0} \boldsymbol{\mu M}$ & $\mathbf{1 0 0} \boldsymbol{\mu M}$ & $\mathbf{2 0 0} \boldsymbol{\mu M}$ & $\mathbf{1 0 \mu M}$ & $\mathbf{2 5} \boldsymbol{M}$ \\
\hline Efflux ratio value & 2.33 & 2.83 & 2.17 & 0.50 & 2.75 & 2.44 & $\mathbf{5 M}$ \\
\hline
\end{tabular}

ent concentrations of capsaicin $(50,100$, and $200 \mu \mathrm{M})$ and piperine $(10,25$, and $50 \mu \mathrm{M})$.

Capsaicin mediated a slight increase in the permeation of FD4 across the excised nasal epithelial tissues at the concentrations applied in this study, as shown in > Fig. 4, and no statistically significant differences were evident. This indicated that the tight junction modulation effect of capsaicin to increase the paracellular permeation of FD4, a macromolecular model compound, was much lower in the excised sheep nasal tissue model compared to the nasal epithelial RPMI cell model ( $\bullet$ Fig. 2). Piperine increased FD4 permeation in the absorptive direction to a larger extent than capsaicin, but it was still not statistically significant. The less pro- nounced effect of the selected pepper extracts on FD4 permeation across the excised sheep nasal tissue as compared to the nasal epithelial RPMI 2650 cell layers may be explained by the differences in the inherent properties of the two models. In contrast to nasal epithelial cell models (e.g., RPMI 2650), animal excised tissues have ciliated cells and goblet cells, and mucus can be present [15]. Mucus plays an important role in the permeation of compounds, especially large molecules such as FD4, across biological membranes.

Both capsaicin and piperine caused pronounced concentration-dependent increases in the absorptive permeation of R123 and mediated a reduction in R123 permeation in the secretory 


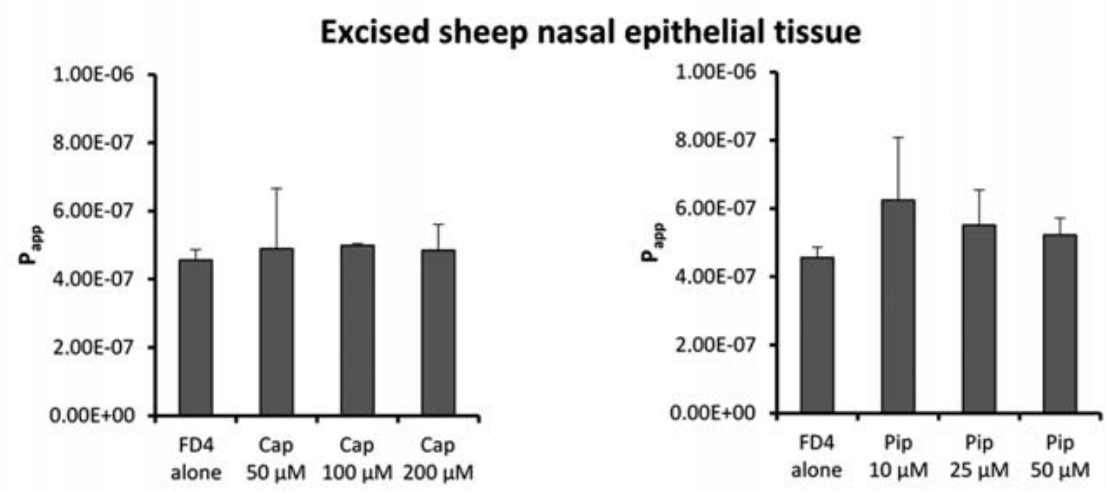

- Fig. $4 \mathrm{P}_{\text {app }}$ values for FD4 in the absence (FD4 alone, control) and presence of different concentrations of capsaicin (Cap) and piperine (Pip) across excised sheep nasal epithelial tissue in the absorptive direction.

\section{Excised sheep nasal epithelial tissue}
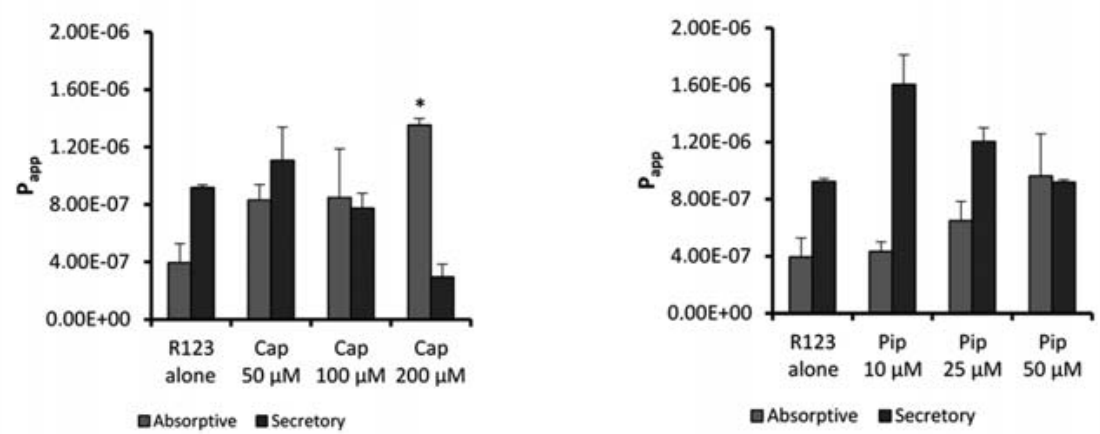

- Fig. $5 \mathrm{P}_{\text {app }}$ values of R123 in the presence of capsaicin (Cap) and piperine (Pip) across sheep nasal mucosa in absorptive and secretory directions $\left({ }^{*} \mathrm{p} \leq 0.05\right.$, Kruskal-Wallis test followed by Dunn's post hoc test).

- Table 4 Efflux ratios of R123 in the absence (control) and presence of different concentrations of capsaicin and piperine across excised sheep nasal epithelial tissue.

\begin{tabular}{|c|c|c|c|c|c|c|c|}
\hline & \multirow[t]{2}{*}{ R123 alone } & \multicolumn{3}{|c|}{ Capsaicin } & \multicolumn{3}{|c|}{ Piperine } \\
\hline & & $50 \mu \mathrm{M}$ & $100 \mu \mathrm{M}$ & $200 \mu \mathrm{M}$ & $10 \mu \mathrm{M}$ & $25 \mu \mathrm{M}$ & $50 \mu \mathrm{M}$ \\
\hline Efflux ratios & 2.34 & 1.33 & 0.91 & 0.22 & 3.70 & 1.86 & 0.95 \\
\hline
\end{tabular}

direction across excised sheep nasal epithelial tissues ( $\bullet$ Fig. 5). When the experimental transport values are compared to that of the controls it is evident that the efflux ratio values had decreased $(\vee$ Table 4$)$. These results clearly show that both capsaicin and piperine exhibit P-gp-related efflux inhibitory properties in excised nasal epithelial mucosa, which means that the absorption of efflux transporter substrates can be improved by coadministration of these pepper extract components. The improved absorption of efflux transporter substrates in the presence of capsaicin and piperine suggests that these substrates can be administered via the nasal route at lower concentrations and still attain similar blood plasma levels.
It has been shown previously that piperine has the ability to inhibit CYP3A4 metabolism, which has been proven in a variety of in vitro and in vivo models $[2,6,25]$. This has also been shown for capsaicin in an in vivo model [23]. The metabolism inhibition effects of these pepper extracts should also be investigated after nasal administration in future studies to elucidate if the metabolism inhibitory effects contribute to their drug absorption enhancing effects.

MTT assays were employed on the RPMI 2650 cell line to evaluate the cytotoxicity effects of capsaicin and piperine on nasal epithelial cells. This is an important consideration in order to establish if the selected pepper extract components have cytotoxic- 


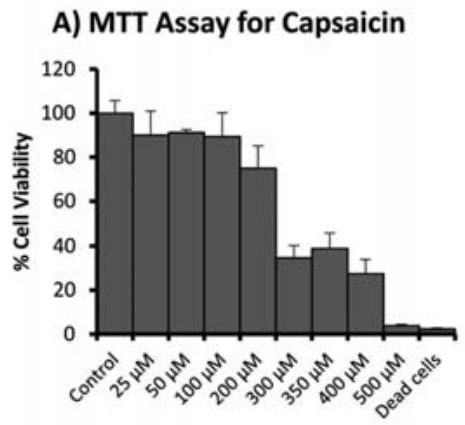

B) MTT assay for Piperine

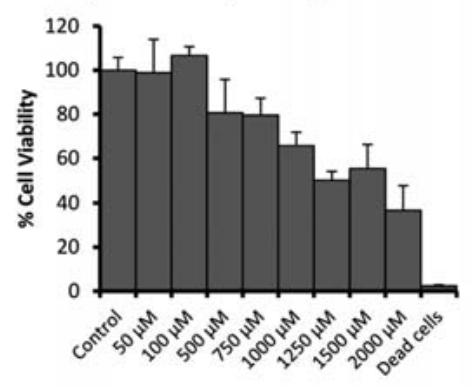

- Fig. 6 Percentage cell viability as determined with an MTT assay on RPMI 2650 cells after $24 \mathrm{~h}$ exposure to a range of (A) capsaicin and (B) piperine concentrations.

ity effects that can cause damage at the concentrations where they are effective as drug absorption enhancers across nasal epithelial surfaces.

According to the ISO 10993-5:2009 standards determined for “Tests for in vitro cytotoxicity" [27], from — Fig. 6A, one can see that capsaicin is not cytotoxic to RPMI 2650 cells up to a concentration of $100 \mu \mathrm{M}$ (cell viability above $80 \%$ ), weakly cytotoxic at a concentration of $200 \mu \mathrm{M}$ (cell viability between $60-80 \%$ ), and highly cytotoxic from $300 \mu \mathrm{M}$ and above (cell viability below $40 \%$ ). Piperine, on the other hand ( $\vee$ Fig. $6 \mathrm{~B}$ ), is considered noncytotoxic to RPMI 2650 cells up to a concentration of $750 \mu \mathrm{M}$. The difference in toxicity between the two pepper extract components can potentially be related to the pungency of the extracts measured in Scoville heat units. The Scoville heat unit scale is used to depict the relative pungency of a pepper. Pure capsaicin possesses a pungency of $16 \times 10^{6}$ Scoville heat units [1], which is much higher than that of piperine at $2 \times 10^{5}$ Scoville heat units [5]. Furthermore, capsaicin and piperine are both proven agonists of the TRPV1 ion channel, which is responsible for the transmittance of multiple noxious stimuli. It is known that the pungency (i.e., the total Scoville heat units) of TRPV1 agonists is directly proportionate to the activation of the receptor $[28,29]$. Caterina et al. [28] found that capsaicin kills both neuronal and non-neuronal cells that express vanilloid receptors through cytoplasmic swelling, an amalgamation of the contents with eventual lysis due to increased receptor activation.

Histological analysis of both RPMI 2650 cell layers grown with the ALI technique and excised sheep nasal epithelial tissues were conducted in the absence (control) and presence of capsaicin and piperine to establish whether any physical changes occurred in the cells or tissues during the permeation experiments.

The histological investigation revealed that RPMI 2650 cells cultured under ALI conditions on porous membranes formed multilayered epithelial surfaces without differentiation into different types of cells that are found in the normal nasal epithelial mucosa. There is no evidence of columnar cells with any specialized modifications, such as goblet and ciliated cells. All cells have a round or slightly elliptical shape. Nuclei are dense without heterochromatin and euchromatin segregation, which is usually associated with the absence of secretory activity. Indeed, no mucus secretion was ob- served, which was confirmed by the absence of Alcian Blue staining. On some areas of the RPMI epithelial cell layers, spaces are visible between the cells, resulting in a less dense aggregation of cells. Exposure to KRB for $180 \mathrm{~min}$ as well as $50 \mu \mathrm{M}$ capsaicin and $50 \mu \mathrm{M}$ piperine did not show any signs of adverse effects on the cell layers in any way ( $\vee$ Fig. 7 B, C, F). Signs of cell loosening or detachment started to appear after exposure to $100 \mu \mathrm{M}$ capsaicin

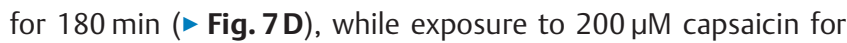
180 min resulted in damage to the cell layers, evidenced by the formation of sinusoids ( $\mathbf{F i g . 7 E}$ ), which is in coherence with MTT results.

The excised sheep nasal epithelial tissues presented as pseudostratified ciliated columnar epithelium with mucus-producing goblet cells present. Epitheliocytes have an elongated shape with cilia on the apical side (free surface) of the tissue. Nuclei are loose with visible nucleoli that indicate an active synthesis process in the tissue cells. Underneath the ciliated epithelial layer, connective tissue with serous glands and blood vessels are visible ( $\vee$ Fig. $8 \mathrm{~A}$ ). After exposure to KRB, all the epithelial tissue structures remained intact with no obvious signs of tissue damage ( Fig. 8B). Furthermore, the underlying tissue layers including the connective tissue, blood vessels, and serous glands did not show signs of necrosis, edema, or hemorrhage after 180 min exposure to $200 \mu \mathrm{M}$ capsaicin and $50 \mu \mathrm{M}$ piperine. However, the epithelial layer was altered after exposure to $200 \mu \mathrm{M}$ capsaicin with excessive cell loss ( $\vee$ Fig. 8C). The columnar cell layer appears to be separated from the rest of the tissue distal to the germ layer. Incubation of sheep nasal tissue with piperine $50 \mu \mathrm{M}$ did not have any adverse effects on the excised sheep nasal epithelium and all structures appeared to be the same as in the intact control tissue ( $\vee$ Fig. 8D).

A histometrical analysis was conducted on both the RPMI 2650 and excised sheep nasal epithelial models, and the values of the parameters that were measured are shown in $>$ Table 5 . The thickness of the whole excised sheep mucosal tissues ranged between $553.4 \pm 65.8$ and $683.6 \pm 336.1 \mu \mathrm{m}$, while the thickness of the sheep nasal epithelial layer alone was $52.9 \pm 4.4 \mu \mathrm{m}$. This compares well with the RPMI 2650 cell layers, where the epithelial thickness ranged between $47.7 \pm 2.5$ and $58.5 \pm 4.34 \mu \mathrm{m}$. The epithelial thickness and average epitheliocyte nuclei areas were comparable between the intact control and after piperine expo- 


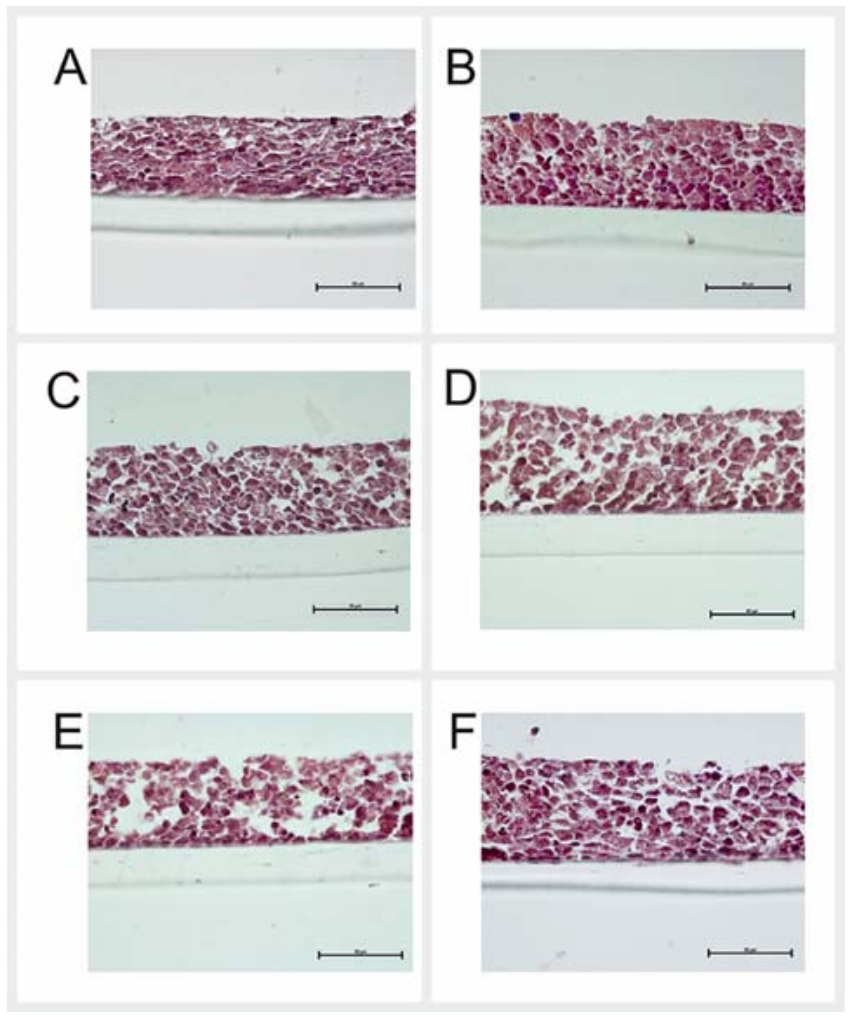

- Fig. 7 Representative histological sections of RPMI 2650 cell layers grown at ALI. A Intact RPMI 2650 cell layer before permeation experiment. B RPMI 2650 cell layer after 180 min exposure to $\mathrm{KRB}$, i.e., in the absence of capsaicin and piperine (control). C RPMI 2650 cell layer after $180 \mathrm{~min}$ exposure to $50 \mu \mathrm{M}$ capsaicin. D RPMI 2650 cell layer after 180 min exposure to $100 \mu \mathrm{M}$ capsaicin. E RPMI 2650 cell layer after $180 \mathrm{~min}$ exposure to $200 \mu \mathrm{M}$ capsaicin. F RPMI 2650 cell layer after $180 \mathrm{~min}$ exposure to $50 \mu \mathrm{M}$ piperine. Scale bar $=50 \mu \mathrm{m}$.

sure for both the excised sheep tissue and RPMI 2650 cell models. However, the thickness of the epithelial layer and the nucleus area of epitheliocytes was dramatically decreased after exposure to capsaicin.

\section{Materials and Methods}

\section{Cell lines and chemicals}

The RPMI 2650 (nasal septum carcinoma) cell line was purchased from the ATCC. FITC-dextran (MW 4400, FD4), R123, capsaicin (purity $>91 \%$ by HPLC against a reference standard), piperine (purity $>97 \%$ by HPLC against a reference standard), hematoxylin-eosin, and $1 \%$ Alcian Blue were purchased from Sigma-Aldrich. Krebs-Ringer bicarbonate buffer was prepared according to Sigma-Aldrich's product information sheet [30]. PBS, MEM, and FBS were purchased from Thermo Fischer, while L-glutamine, PenStrep, nonessential amino acids, and trypsin-EDTA $(0.25 \% \mathrm{w} / \mathrm{v})$ were purchased from Whitehead Scientific. MTT, hematoxylin solution (GHS132), Eosin Y solution, and aqueous (HT110216) and Alcian Blue solution (B8438) were purchased from Sigma-Aldrich.
ThinCert 12-well plates (catalogue number 665110) and PTPcoated inserts (catalogue number 665641) were purchased from Separation Scientific. Sheep (Merino, Dorper or Île-de-France subject to availability) nasal tissue was collected from a local abattoir in Potchefstroom, South Africa.

\section{Chemical characterization of capsaicin and piperine raw materials}

The purity of the purchased piperine and capsaicin raw materials was determined by means of liquid chromatography analysis using an Agilent 1100 series HPLC equipped with a gradient pump, autosampler, UV detector, and OpenLab CDS Chemstation Rev. C.01.07 SR3 data acquisition and analysis software (Agilent Technologies). HPLC conditions were adapted from the literature and were as follows: USP L1, Venusil XBP C18 column, $150 \times 4.5 \mathrm{~mm}$, $5 \mu \mathrm{m}$ (Agela Technologies) with the mobile phase as $\mathrm{ACN} / \mathrm{H}_{2} \mathrm{O}$ with $0.1 \% \mathrm{H}_{3} \mathrm{PO}_{4} 60: 40$ at a flow rate of $1.0 \mathrm{~mL} / \mathrm{min}$ for both capsaicin and piperine. Both injection volumes were set at $10 \mu \mathrm{L}$ per sample. For capsaicin, the detection wavelength was set at $225 \mathrm{~nm}$ and it eluted at a retention time of $\pm 5.28 \mathrm{~min}$ [31], whereas a wavelength of $325 \mathrm{~nm}$ was used for piperine with a retention time of \pm 5.18 min [5].

The linearity of capsaicin and piperine reference standards were determined first followed by a purity analysis. The purity of the raw materials was determined against the reference standard for each extract using Equation 1 where the reference standard concentrations were $250 \mu \mathrm{g} / \mathrm{mL}$ for capsaicin and $150 \mu \mathrm{g} / \mathrm{mL}$ for piperine.

$\%$ Purity of pepper ectract $=\frac{\text { experimental concentration }}{\text { reference standard concentration }} \times 100$

(Eq. 1)

\section{Fluorescence spectroscopic analysis of FITC-dextran and rhodamine 123}

Fluorescence spectroscopic analysis was used to determine FD4 and R123 in the permeation samples and the analyses were done using a Spectramax Paradigm (serial nr. 33270-1142) multimode detection platform plate reader. FD4 was analyzed with excitation and emission wavelengths set at $485 \mathrm{~nm}$ and $525 \mathrm{~nm}$ [10, 32], respectively, while R123 was analyzed using $480 \mathrm{~nm}$ excitation and $520 \mathrm{~nm}$ emission wavelengths [33, 34]. The fluorescence analytical methods were validated for linearity, accuracy, and precision.

\section{Cell culturing}

RPMI 2650 cell layers were cultured on ThinCert insert membranes by means of the ALI technique using previously published methods $[8,11,35]$ with some slight modifications.

Briefly, RPMI 2650 cells were first grown in culture flasks using MEM fortified with $10 \%$ FBS and $1 \%$ each of PenStrep, nonessential amino acids, and L-glutamine. Cells were maintained in a humidified $5 \% \mathrm{CO}_{2}$ atmosphere at $37^{\circ} \mathrm{C}$ with media changes every 2 days. After confluency of approximately $90 \%$ was reached in the culture flasks, cells were washed twice with $10 \mathrm{~mL}$ PBS and then trypsinized with $0.25 \%(w / v)$ trypsin-EDTA for 5 min in an incubator. Cells were then counted using a hemocytometer and seeded into PTP-coated ThinCert inserts $\left(113.1 \mathrm{~mm}^{2}\right.$ culture surface, $0.4 \mu \mathrm{m}$ pore size, $2 \times 10^{6} \cdot \mathrm{cm}^{-2}$ pore density) at a density of 
$6 \times 10^{5}$ cells $/ \mathrm{cm}^{2}$. Seeding was done with cells between the passages of 25 and 47 .

Culturing in the 12-well ThinCert culture plates took place for a total of 21 days with media changes every 2 days. Cells were cultured under LCC conditions for the first 2 days, allowing cells to adhere to the membrane. LCC conditions entail media being present at both the apical $(0.8 \mathrm{~mL})$ and basolateral (approximately $4 \mathrm{~mL}$ ) side of the membrane. After 2 days, during the first media change, cells were lifted to ALI conditions. ALI conditions entail media (approximately $4 \mathrm{~mL}$ ) to only be added to the basolateral side of the membrane for a period of 19 days. After a total of 21 days, the inserts were carefully transferred to 12-well ThinCert transport plates, the TEER across each cell layer on insert membrane was measured, and permeation studies were then initiated.

\section{Collection and excision of sheep nasal epithelial tissue}

Approval from the North-West University's animal ethics committee (AnimCare) was obtained for the use of excised sheep nasal tissue in the permeation experiments (ethics approval certificate nr. NWU-00285-17-A5). The removal of sheep nasal mucosal tissue was accomplished via a method that was adapted from previously published methods for excision of nasal epithelial tissues from different animals [15, 36-38].

After slaughter, the anterior portion of the skull (i.e., the snout) was removed via a longitudinal incision along the frontal plane, anterior to the eyes. The skin was then removed from the snout via dissection, and the snout specimen was rinsed and submerged in ice-cold KRB and transported to the laboratory. In the laboratory, a vertical incision was made along the septal midline in order to remove the septum. After separation into two halves, a vertical incision was made through the lateral wall of the snout, just posterior to the incisura nasoincisiva in order to isolate the nasal conchae. Hereafter, the nasal epithelial tissue layer was separated from the conchae cartilage via blunt dissection.

The pieces of epithelium were laid out on moistened filter paper in order to facilitate easier handling and to prevent damage to the epithelial cells. Strips of tissue were then cut in widths of approximately $1 \mathrm{~cm}$ each and mounted in Sweetana-Grass diffusion chambers after filter paper removal.

\section{Ex vivo permeation studies}

All permeation studies of R123 and FD4 in the absence (control groups) and presence of capsaicin or piperine were done in both of the nasal epithelial models (i.e., RPMI 2650 cell layers grown on insert membranes and excised sheep nasal tissues mounted in Sweetana Grass diffusion chambers) in triplicate.

For the RPMI 2650 cell model, succeeding the 21 days in culture, permeation studies were slightly adapted from previously published methods $[8,10,12]$. Firstly, the PTP-coated ThinCert inserts were transferred from 12-well culture plates to 12-well transport plates while maintaining sterile conditions. A volume of $0.8 \mathrm{~mL}$ preheated $\left(37^{\circ} \mathrm{C}\right) \mathrm{KRB}$ was added to the apical compartment and $1.8 \mathrm{~mL} \mathrm{KRB}$ to the basolateral compartment. The 12well transport plates were then left to equilibrate for $15 \mathrm{~min}$ in an incubator. For permeation studies in the absorptive (apical-tobasolateral) direction, $0.8 \mathrm{~mL}$ of the selected marker compound (i.e., either FD4 or R123) in the presence of the selected pepper

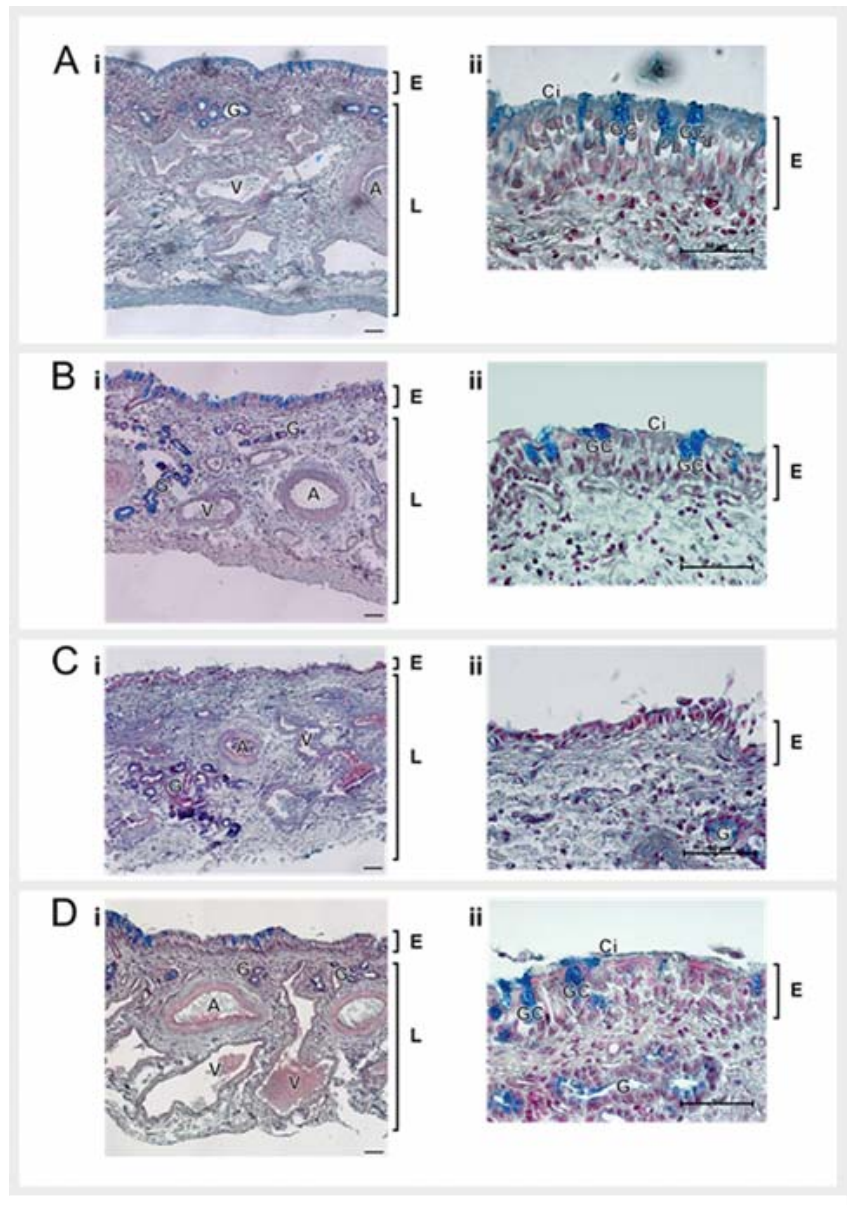

- Fig. 8 Representative histological sections of excised sheep nasal epithelial tissues with column $\mathrm{i}$ indicating the whole excised tissue and column ii only the epithelial layer at a higher magnification. A Intact excised sheep nasal epithelial tissue before permeation experiment. B Excised sheep nasal epithelial tissue after $180 \mathrm{~min}$ exposure to KRB. C Excised sheep nasal epithelial tissue after 180 min exposure to $200 \mu \mathrm{M}$ capsaicin. D Excised sheep nasal epithelial tissue after $180 \mathrm{~min}$ exposure to $50 \mu \mathrm{M}$ piperine. Legend: A - arteries, Ci - cilia, E - epithelial layer, G - serous glands, $\mathrm{GC}$ - goblet cells, L - lamina propria, $\mathrm{V}$ - veins. Scale bar $=50 \mu \mathrm{m}$.

extract component (i.e., either capsaicin or piperine) suspended in KRB was applied and incubated on the apical side of the membrane. Samples of $180 \mu \mathrm{L}$ were withdrawn from the basolateral side at the time intervals of $5,10,15,30,60,90,120$, and 180 min and immediately replaced with an equal volume of fresh KRB after each withdrawal. Similarly, for permeation studies in the secretory (basolateral-to-apical) direction, $1.8 \mathrm{~mL}$ test solution was applied and incubated on the basolateral side. Samples of $180 \mu \mathrm{L}$ were withdrawn from the apical side at the time intervals of $5,10,15,30,60,90,120$, and $180 \mathrm{~min}$ and immediately replaced with an equal volume of fresh KRB after each withdrawal.

Permeation studies across excised sheep nasal epithelial tissue in the Sweetana-Grass diffusion chambers were done in a similar fashion. After assembly of the diffusion chambers, $7 \mathrm{~mL}$ preheated $\left(34^{\circ} \mathrm{C}\right) \mathrm{KRB}$ were incubated at both sides of the membrane, connected to a heating block and carbogen $\left(95 \% \mathrm{O}_{2}: 5 \%\right.$ 
- Table 5 Parameters of epithelia of two different nasal tissue models ( ${ }^{*}$ statistically significant differences compared to the control group with $\mathrm{p} \leq 0.01)$.

\begin{tabular}{|l|c|c|}
\hline & Intact control & Capsaicin, $200 \mu M$ \\
\hline Excised mucosa thickness $(\mu \mathrm{m})$ & Excised sheep tissue & \multicolumn{1}{|c|}{ Piperine, $\mathbf{5 0} \boldsymbol{\mu M}$} \\
\hline Epithelial thickness $(\mu \mathrm{m})$ & $683.6 \pm 336.1$ & $18.8 \pm 7.4^{*}$ \\
\hline Average epitheliocyte nucleus area $\left(\mu \mathrm{m}^{2}\right)$ & $52.9 \pm 4.4$ & $22.2 \pm 8.2^{*}$ \\
\hline & $36.1 \pm 6.6$ & $47.5 \pm 9.1$ \\
\hline Epithelial thickness $(\mu \mathrm{m})$ & RPMI 2650 cell layers grown with ALI technique \\
\hline Average epitheliocyte nuclei area $\left(\mu \mathrm{m}^{2}\right)$ & $53.3 \pm 8.1$ & $47.7 \pm 2.5^{*}$ \\
\hline
\end{tabular}

$\mathrm{CO}_{2}$ ) supply to equilibrate for $15 \mathrm{~min}$. Permeation studies in the absorptive direction contained $7 \mathrm{~mL}$ test solution in the apical chamber and $7 \mathrm{~mL}$ KRB in the basolateral chamber, while for secretory permeation studies, the $7 \mathrm{~mL}$ test solution was applied to the basolateral chamber and $7 \mathrm{~mL}$ KRB in the apical chamber. Samples were withdrawn at the same volume and time intervals as described for the permeation studies on the RPMI 2650 cell model.

Following analysis of samples using a Spectramax Paradigm plate reader for either FD4 or R123 concentrations, the percentage transport (Eq. 2) and the $\mathrm{P}_{\text {app }}$ values were calculated (Eq. 3).

$\%$ Transport $=\frac{\text { Conc. value at specific time }}{\text { Conc. value of donor solution }} \times 100$

$P_{\mathrm{app}}=\frac{\mathrm{dQ}}{\mathrm{dt}}\left(\frac{1}{\mathrm{~A} \cdot 60 \cdot \mathrm{C}_{0}}\right)$

Where $P_{a p p}$ is the apparent permeability coefficient $\left(\mathrm{cm} \times \mathrm{s}^{-1}\right)$, $\frac{d Q}{d t}$ is the permeability rate per minute, $A$ is the diffusion area of the membrane $\left(\mathrm{cm}^{2}\right)$, and $C_{0}$ is the initial concentration of each marker compound used.

The efflux ratio of the P-gp substrate, R123, was also calculated in order to determine the extent to which peppers are able to modulate efflux proteins (Eq. 4).

$E R=\frac{P_{\text {app }}(\text { secretory })}{P_{\text {app }}(\text { absorptive })}$

\section{Cytotoxicity and histology}

An MTT assay was performed to determine cytotoxicity on RPMI 2650 cells based on previously published $[9,39]$ methods. Cells were seeded in a clear bottom 96 -well plate at a density of $3 \times 10^{5}$ cells $/ \mathrm{cm}^{2}$ and left to attach for $24 \mathrm{~h}$. Both capsaicin (25$500 \mu \mathrm{M})$ and piperine $(50-2000 \mu \mathrm{M})$ were prepared in MEM, added to the cells after attachment, and left to incubate at $37^{\circ} \mathrm{C}$ in a $5 \% \mathrm{CO}_{2}$ humidified atmosphere for $24 \mathrm{~h}$. Following drug exposure, the cells were washed twice with $100 \mu \mathrm{L}$ PBS. Thereafter, $180 \mu \mathrm{L}$ non-additive MEM were added to the cells, followed by $20 \mu \mathrm{L}$ of $5 \mathrm{mg} / \mathrm{mL}$ MTT in PBS. Plates were then returned to the incubator for $4 \mathrm{~h}$. Following the assay, the media was aspirated from all wells and crystals were dissolved in $200 \mu \mathrm{L}$ DMSO. The plates were then placed on an orbital shaker for $1 \mathrm{~h}$ and absorbance was measured at two wavelengths, 560 and $630 \mathrm{~nm}$, for cell signal and background noise, respectively, using a Spectramax Paradigm ${ }^{\circledR}$ plate reader. All experiments were done in triplicate.

Histological analysis was conducted to determine the effects of the pepper extract components on both the RPMI 2650 cell layers and the excised sheep nasal epithelial tissues following exposure during the permeation studies in triplicate. Excised sheep nasal tissue samples before permeation (intact control) and after the $3 \mathrm{~h}$ permeation studies were fixed in $10 \%$ buffered formalin at $+4{ }^{\circ} \mathrm{C}$ for $24 \mathrm{~h}$. RPMI $2650 \mathrm{ALI}$ cell layers on ThinCert insert membranes before permeation (intact control) and after the $3 \mathrm{~h}$ permeation studies were washed with PBS and fixed in $10 \%$ buffered formalin at room temperature for $1 \mathrm{~h}$. The samples were then dehydrated in a graded series of ethanol and embedded in paraffin, sliced into 4-5 $\mu \mathrm{m}$ sections, stained with hematoxylin-eosin and $1 \%$ Alcian Blue, and then examined under a Nikon E800 compound microscope using $60 \times$ objective. The sheep mucosa thickness, epithelial thickness, and nucleic area of the epitheliocytes were measured from five different sections per sample using NIS-Elements, Version 4.05 software.

\section{Statistical analysis}

Statistical analysis was performed using Statistica v. 13.3 (StatSoft, Inc.). Data are presented as the mean \pm SD. Data analysis of the $P_{\text {app }}$ values for all test groups and in both models as well as histological parameters was performed using Kruskal-Wallis tests for comparison of multiple groups followed by Dunn's test for comparison of two groups. $\mathrm{P} \leq 0.05$ was considered to represent a statistically significant difference.

\section{Acknowledgements}

This work is based on the research supported by the National Research Foundation of South Africa (Grant numbers: 98939, 109284, and 118418).

\section{Conflict of Interest}

The authors declare no conflict of interest. 


\section{References}

[1] Baenas N, Belović M, Ilic N, Moreno DA, García-Viguera C. Industrial use of pepper (Capsicum annum L.) derived products: Technological benefits and biological advantages. Food Chem 2019; 274: 872-885

[2] Srinivasan K. Black pepper and its pungent principle-piperine: a review of diverse physiological effects. Crit Rev Food Sci Nutr 2007; 47: 735-748

[3] Omolo MA, Wong ZZ, Mergen AK, Hastings JC, Le NC, Reiland HA, Case KA, Baumler DJ. Antimicrobial properties of chili peppers. J Infect Dis Ther 2014; 2: 1000145

[4] Han Y, Tan TMC, Lim LY. Effects of capsaicin on P-gp function and expression in Caco-2 cells. Biochem Pharmacol 2006; 71: 1727-1734

[5] Upadhyay V, Sharma N, Joshi HM, Malik A, Mishra M, Singh BP, Tripathi S. Development and validation of rapid RP-HPLC method for estimation of piperine in Piper nigrum L. Int J Herb Med 2013; 1: 6-9

[6] Bhardwaj RK, Glaeser H, Becquemont L, Klotz U, Gupta SK, Fromm MF. Piperine, a major constituent of black pepper, inhibits human P-glycoprotein and CYP3A4. J Pharmacol Exp Ther 2002; 302: 645-650

[7] Li C, Wang Q, Ren T, Zhang Y, Lam CWK, Chow MSS, Zuo Z. Non-linear pharmacokinetics of piperine and its herb-drug interactions with docetaxel in Sprague-Dawley rats. J Pharm Biomed Anal 2016; 128: 286-293

[8] Kreft ME, Jerman UD, Lasič E, Rižner TL, Hever-Kene N, Peternel L, Kristan K. The characterization of the human nasal epithelial cell line RPMI 2650 under different culture conditions and their optimization for an appropriate in vitro nasal model. Pharm Res 2015; 32: 665-679

[9] Lungare S, Bowen J, Badhan R. Development and evaluation of a novel intranasal spray for the delivery of amantadine. J Pharm Sci 2016; 105: 1209-1220

[10] Wengst A, Reichl S. RPMI 2650 epithelial model and three-dimensional reconstructed human nasal mucosa as in vitro models for nasal permeation studies. Eur J Pharm Biopharm 2010; 74: 290-297

[11] Dolberg AM, Reichl S. Expression of P-glycoprotein in excised human nasal mucosa and optimized models of RPMI 2650 cells. Int J Pharm 2016; 508: 22-33

[12] Pozzoli M, Ong HX, Morgan L, Sukkar M, Traini D, Young PM, Sonvico F. Application of RPMI 2650 nasal cell model to a 3D printed apparatus for the testing of drug deposition and permeation of nasal products. Eur J Pharm Biopharm 2016; 107: 223-233

[13] Soane RJ, Hinchcliffe M, Davis SS, Illum L. Clearance characteristics of chitosan based formulations in the sheep nasal cavity. Int J Pharm 2001; 217: $183-191$

[14] Kim DD. In vitro cellular Models for nasal Drug Absorption Studies. In: Ehrhardt C, Kim KJ, eds. Drug Absorption Studies. New York: Springer; 2008: 216-234

[15] Schmidt MC, Peter H, Lang SR, Ditzinger G, Merkle HP. In vitro cell models to study nasal mucosal permeability and metabolism. Adv Drug Deliv Rev 1998; 29: 51-79

[16] Nagumo Y, Han J, Arimoto M, Isoda H, Tanaka T. Capsaicin induces cofilin dephosphorylation in human intestinal cells: the triggering role of cofilin in tight-junction signaling. Biochem Biophys Res Commun 2007; 355: 520-525

[17] Nagumo Y, Han J, Bellila A, Isoda H, Tanaka T. Cofilin mediates tightjunction opening by redistributing actin and tight-junction proteins. Biochem Biophys Res Commun 2008; 377: 921-925

[18] Kanda Y, Yamasaki Y, Sasaki-Yamaguchi Y, Ida-Koga N, Kamisuki S, Sugawara F, Nagumo Y, Usui T. TRPA1-dependent reversible opening of tight junction by natural compounds with an $\alpha, \beta$-unsaturated moiety and capsaicin. Sci Rep 2018; 8: 1-13

[19] Shiobara T, Usui T, Han J, Isoda H, Nagumo Y. The reversible increase in tight junction permeability induced by capsaicin is mediated via cofilinactin cytoskeletal dynamics and decreased level of occluding. PLoS One 2013; 8: e79954
[20] Eigenmann DE, Dürig C, Jähne EA, Smieško M, Culot M, Gosselet F, Cecchelli R, Helms HCC, Brodin B, Wimmer L, Mihovilovic MD, Hamburger $\mathrm{M}$, Oufir $\mathrm{M}$. In vitro blood-brain barrier permeability predictions for $\mathrm{GABA}_{\mathrm{A}}$ receptor modulating piperine analogs. Eur J Pharm Biopharm 2016; 103: 118-126

[21] Khajuria A, Thusu N, Zutshi U. Piperine modulates permeability characteristics of intestine by inducing alterations in membrane dynamics: influence on brush border membrane fluidity, ultrastructure and enzyme kinetics. Phytomed 2002; 9: 224-231

[22] Nabekura T, Kamiyama S, Kitagawa S. Effects of dietary chemoprotective phytochemicals on P-glycoprotein function. Biochem Biophys Res Commun 2005; 327: 866-870

[23] Zhai XJ, Shi F, Chen F, Lu YN. Capsaicin pretreatment increased the bioavailability of cyclosporin in rats: involvement of P-glycoprotein and CYP 3A inhibition. Food Chem Toxicol 2013; 62: 323-328

[24] Han Y, Tan TMC, Lim LY. In vitro and in vivo evaluation of the effects of piperine on P-gp function and expression. Toxicol Appl Pharmacol 2008; 230: 283-289

[25] Jin MJ, Han HK. Effect of piperine, a major component of black pepper, on the intestinal absorption of fexofenadine and its implication on food-drug interaction. J Food Sci 2010; 75: H93-H96

[26] Takizawa Y, Kitazato T, Ishizaka H, Kamiya N, Ito Y, Kishimoto H, Tomita M, Hayashi M. Changes in absorption and excretion of rhodamine 123 by sodium nitroprusside. Int J Pharm 2013; 450: 31-35

[27] López-García J, Lehocký M, Humpolíček P, Sáha P. HaCaT keratinocytes response on antimicrobial atelocollagen substrates: extent of cytotoxicity, cell viability and proliferation. J Func Biomater 2014; 5: 43-57

[28] Caterina MJ, Schumacher MA, Tominaga M, Rosen TA, Levine JD, Julius D. The capsaicin receptor: a heat-activated ion channel in the pain pathway. Nature 1997; 389: 816-824

[29] Ursu D, Knopp K, Beattie RE, Liu B, Sher E. Pungency of TRPV1 agonists is directly correlated with kinetics of receptor activation and lipophilicity. Eur J Pharmacol 2010; 641: 114-122

[30] [Anonymous]. Krebs-Ringer bicarbonate buffer. Product information sheet. Available at https://www.sigmaaldrich.com/content/dam/ sigma-aldrich/docs/Sigma/Product_Information_Sheet/1/k4002pis.pdf. Accessed November 11, 2018

[31] Othman ZAA, Ahmed YBH, Habila MA, Ghafar AA. Determination of capsaicin and dihydrocapsaicin in Capsicum fruit samples using high performance liquid chromatography. Molecules 2011; 16: 8919-8929

[32] Nakamura K, Maitani Y, Takayama K. The enhancing effect of nasal absorption of FITC-dextran 4,400 by $\beta$-sitosterol $\beta$-D-glucoside in rabbits. J Control Release 2002; 79: 147-155

[33] Gerber W, Hamman JH, Steyn JD. Excipient-drug pharmacokinetic interactions: Effect of disintegrants on efflux across excised pig intestinal tissues. J Food Drug Anal 2018; 26: S115-S124

[34] Kaprelyants AS, Kell DB. Rapid assessment of bacterial viability and vitality by rhodamine 123 and flow cytometry. J Appl Bacteriol 1992; 72: 410-422

[35] Dolberg AM, Reichl S. Activity of multidrug resistance-associated proteins 1-5 (MRP 1-5) in the RPMI 2650 cell line and explants of human nasal turbinate. Mol Pharm 2017; 14: 1577-1590

[36] Chung FY, Donovan MD. Nasal pre-systemic metabolism of peptide drugs: substance $\mathrm{P}$ metabolism in the sheep nasal cavity. Int J Pharm 1996; 128: 229-237

[37] Pund S, Rasve G, Borade G. Ex vivo permeation characteristics of venlafaxine through sheep nasal mucosa. Eur J Pharm Sci 2013; 48: 195-201

[38] Rathman G, Narayanan N, Ilavarasan R. Carbopol-based gels for nasal delivery of progesterone. AAPS PharmSciTech 2008; 9: 1078-1082

[39] Wang X, Meng M, Gao L, Liu T, Xu Q, Zeng S. Permeation of astilbin and taxifolin in Caco-2 cell and their effects on the P-gp. Int J Pharm 2009; 378: $1-8$ 